\title{
Hydraulic engineering analysis of Roman water infrastructure: a review of practice and possibilities
}

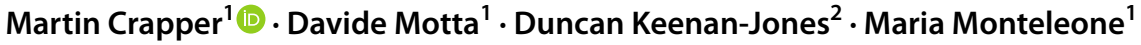

Received: 8 September 2020 / Accepted: 14 September 2021 / Published online: 8 November 2021

(c) The Author(s) 2021

\begin{abstract}
A short review is presented covering English-language publications where quantitative engineering analysis has been used to study and gain insight into how ancient Roman and Mediterranean water systems functioned. The review covers work on using technical engineering perspectives to try and understand the geometrical layout of water systems, quantitative work of a type readily accomplished by undergraduate civil engineering students, such as calculating the flow capacity of aqueducts and other conduits of known dimensions, and more involved studies using computational techniques usually applied by specialist engineers in research or industry. It is concluded that the many different levels of analyses employed have given insight into how Roman water systems worked, for example the amount of water they delivered, and the kinds of issues their designers and operators might have faced. It is hoped that this review will inspire further interdisciplinary study in Archaeohydrology, using modern engineering techniques to amplify and extend the story of Roman water systems told by archaeologists.
\end{abstract}

Keywords Roman · Water · Infrastructure · Aqueduct · Pipe · Engineering · Quantitative · Archaeohydrology

\section{Introduction and context}

Roman water infrastructure such as aqueduct bridges and cisterns has long fascinated scholars and the public alike. The surviving monumental remains across the Mediterranean region speak directly to modern humans who are no less dependent on water than their ancient ancestors, and the flow of archaeological literature continues: a recent online search for "Roman Aqueducts" showed 62 peer-reviewed articles since 2016.

The authors of this review share this fascination. However, three of us are from a background in hydraulic engineering, which we define as the scientific study of the

Martin Crapper

Martin.Crapper@northumbria.ac.uk

1 Department of Mechanical and Construction Engineering, Northumbria University, Newcastle upon Tyne, UK

2 Faculty of Humanities and Social Sciences, School of Historical and Philosophical Inquiry, University of Queensland, Brisbane, Australia 
conveyance of water through pipes or channels, whether natural or artificial. We therefore have a specific interest in gaining a quantitative understanding of how Roman water systems actually functioned. On these matters, however, the standard write-up of archaeological field work, with its commentary on the form and date of remains studied, leaves us frustratingly short on specific technical detail.

In some cases we have provided this ourselves: Crapper has worked on the Roman Colosseum and on the water system of ancient Constantinople (Crapper et al. 2016; Ruggeri et al. 2016, 2017; Ward et al. 2017a, 2017b); Motta and Keenan-Jones have studied flow and travertine deposition in the Anio Novus (Keenan-Jones et al. 2015; Motta et al. 2017); Monteleone has studied the functioning of the fountains of Pompeii (Monteleone et al. 2021). In each case, we have provided quantitative engineering detail informed by our professional backgrounds. All our studies have, we believe, led to insights into Roman water engineering achievements that would not have been possible without the engineering approach. During our work, we have of course come across many excellent examples of earlier research that has attempted to provide quantitative insight, and this has been extremely helpful. It is, however, varied in subject matter and analysis method, and published and indexed in diverse places.

This review is an attempt to draw together a substantial collection of this material. It is specifically aimed at anyone who is interested in how Roman water systems worked, how much water they delivered over days, seasons, and centuries, what kinds of decisions their designers and operators had to make, and why they might have made them. All of these questions depend on technical insights rather than just historical ones. By extension, the review is also aimed at those who wish to gain an appreciation of the different kinds of engineering techniques that have been applied to produce the required technical insights. This will encompass a wide range of readers, including postgraduate students commencing research in either the archaeology or the engineering analysis of ancient water systems, more senior academics from either discipline wanting a swift overview of what has been done, and interested scholars from other disciplines or ordinary members of the public with a technically-oriented curiosity about past achievements in water engineering.

What we hope our readers will take is firstly an understanding of the kind of engineering analysis that is possible, even for ancient systems were documentary evidence is largely non-existent and physical evidence is fragmented and uncertain. We also hope they will gain some understanding of how engineers think and the kinds of information that interests and enables them to apply their quantitative analysis to archaeological problems. This should then inform researchers in other disciplines, notably archaeologists, assisting them to record and report their findings in a way that facilitates future technical analysis using engineering approaches.

We have recently witnessed the foundation of a new interdiscipline named Archaeohydrology, with its own community (archaeohydrology@googlegroups.com) dedicated to the technical analysis of ancient water systems and problems. Nevertheless, there remains a dichotomy between archaeology and engineering - there is, for example, no journal that has an obvious, regular audience in both camps and where readers would regularly be exposed to 'what can be done'. We aim to provide, in one short review paper, an introduction that does this and that will be a short-term conversation starter to further work of this nature. 


\section{Scope of the review}

For reasons of practicality, we have confined our scope specifically to the geographical and region and period we ourselves have studied. This covers Roman water infrastructure, as well as that of other societies such as Nabatean Petra that were contemporaneous with the Roman Empire and were likely to have shared knowledge with it. Many of the authors whose research we discuss have also studied water infrastructure in the Far East and the Americas, for example, often using the same methods as for their Roman works, and whilst we commend those studies to our readers, we have not attempted to review them here in order complete a cohesive and manageable study. We have also confined ourselves to papers written since the 1970s, during which period engineering analysis has attained its modern form with the substantial aid of computers, and in the English language, so that the studies are widely accessible to most of our readers. We acknowledge the range and quality of similar works published in other languages, and though they do not fit our present scope, they would be worthy of a separate review in the future.

\section{Types of engineering analysis and subject matter}

We have set out to review papers where there is clear and specific, quantitative, numerate engineering analysis to complement archaeological findings. Engineering analysis, of course, comes in many forms. This section is intended to give the general reader a feel for the kinds of tasks that might be involved and the likely level of educational background in hydraulic engineering subjects that might be required to complete them.

Some engineering analysis can be quite involved, but not address hydraulics as such. Examples of this type of study of Roman water systems include quantitative spatial analysis using geographical information systems (GIS), for example to examine the slopes of catchments and drainage areas; another example of non-hydraulic engineering analysis is the spectral study of mineral deposits on aqueduct walls with a view to matching them against source water chemistry or radio-carbon dating of the organic inclusions within the deposits. These tasks clearly require suitable education and training, but not in the theoretical knowledge and quantitative skills that characterize hydraulic engineering.

Actual hydraulic engineering analysis begins at a very simple level with mass balance considerations: a "what goes in must come out" type of calculation; it then moves on to the kind of hand-calculations that are approximately at the level of a first- or second-year undergraduate student in civil engineering. These concern steady flows, where variation over time is either not present or not considered in the analysis, and make use of concepts such as the Darcy-Weisbach equation with a Moody friction factor derived from the Colebrook-White equation for flow in pipes or Manning's equation for flow in open channels such as rivers, irrigation canals or Roman aqueducts. These formulae relate the flow of water to the elevation difference or pressure driving it, the size of the conduit or channel through which it travels and the frictional characteristics of the conduit's or channel's inner surface. Once familiar, they are simple to use and are still regularly employed by present-day civil engineers engaged in pipe or channel design. The difficulty usually lies in estimating the friction appropriately, as this depends on 
the surface texture at a micro level, more meso-surface patterns such as ripples, and the flow conditions. For both the design of new and analysis of existing systems, typical values of frictional characteristics derived from empirical experience are often used.

The next stage of analysis involves added complications such as unsteady (time-varying) flow, or flows with spatial transition from subcritical to supercritical and/or vice-versa in open channels. This transition refers to the rapid change from deep and slow to shallow and rapid flow that can readily be observed downstream of a weir in a river, or the change back to deeper and slower flow by means of a type of standing wave called a hydraulic jump, which often occurs a little further downstream from the weir. These processes result in significant issues with forces and energy on hydraulic structures and can thus be a significant problem for designers. They are analysed by applying the principles of conservation of mass, energy and momentum, which is generally possible by hand-calculation. This is also possible at the undergraduate level, though more difficult than the steady flow calculations, and commercially available computer applications are now prevalently employed to solve the necessary equations more rapidly, especially for convoluted conduit or channel geometry.

The remaining forms of hydraulic analysis are all computer dependent and involve the solution of a full system of equations describing the flow. On the one hand, computational fluid dynamics (CFD) can, by applying numerical techniques such as Finite Volume Analysis to solve the full Navier-Stokes equations with various closure models accounting for fluid turbulence, address complicated flow patterns in detail, and in three coordinate dimensions, over relatively small spatial areas such as a single hydraulic structure. On the other hand, simplified systems of equations such as the one-dimensional St. Venant Equations for unsteady open channel flows (which are a simplification in that they analyze flows in one dimension along a channel, neglecting the effects of variation across its width and depth) are utilised within computer packages to solve entire systems of flow such as a river and its tributaries, or the Roman aqueduct equivalent of a main route with side channels joining it.

For a non-specialist requiring an introduction to the principles of hydraulic engineering, many references are available which are accessible to someone of average ability in high school mathematics. A good example is (Chadwick et al. 2013), particularly chapters 2 to 5 and 14. The forms of analysis used in the research we have reviewed can be categorized by the increasing level of educational background in engineering, as set out in Table 1 . We have also reviewed research according to three broad categories of subject matter, as set out in Table 2.

\section{A-hydraulic geometry}

The research reviewed here is not so much concerned with volumes of water, as with determining the arrangement of Roman water structures, conduits, or systems in a way that is an essential precursor to any subsequent hydraulic analysis. This work goes beyond simple archaeology by deriving specific hydraulic parameters such as channel length, bed level and slope, and frictional characteristics of channel walls, which tend to go uncommented in excavation reports.

Most publications in this category are fairly recent, since they tend to depend on modern GIS. An early example is Maktav et al. (2009). This is a study of the Constantinople aqueduct system building on the original archaeological survey work of Çeçen (1996). A global positioning system (GPS) field study was backed up with satellite imagery data to 
Table 1 Categories of hydraulic engineering analysis

Level of educational background in hydraulic engi- Hydraulic engineering analysis neering typically required

None

Education/training in engineering or non-engineering subjects

High school/first year undergraduate

Second year undergraduate

Batchelor's degree

Postgraduate training

Significant research training or industrial experience
No quantitative analysis

Some quantitative analysis, but not generally referring to hydraulics; e.g. spatial analysis using geographical information systems (GIS) only, or spectral analysis of materials

Hydraulic calculations covering mass balance only

Hydraulic analysis of steady flows using Darcy's equation, Manning's equation or similar

Hydraulic analysis considering unsteady flow, or flow with sub- to supercritical transitions or similar, by hand-calculation or very simple computer analysis such as a spreadsheet

Computational fluid dynamics (CFD) or other computer model of an individual element or structure in a hydraulic system

Computational analysis of a whole water system such as a whole aqueduct or an urban distribution network

understand the topography and land use in the catchment that served the Valens Aqueduct of Constantinople; it paved the way to our current understanding of the routes of the different aqueduct channels. Another careful study by Orengo et al. (2013) applied GIS with various interpolation methods combined with historical and archaeological records, to partially reconstruct the water distribution system of the Roman city of Barcino (modern Barcelona). No hydraulic calculations were carried out, but the inclusion of information such as conduit size, slope, length and location is a good basis for a future study.

Recent work on the Constantinople water system has resulted in three studies in this category. Focusing on the area inside the city walls, Ward et al. (2017a) conducted a careful review of evidence on cisterns, identifying a total of 209 within the ancient city but specifically noting important hydraulic details such as their invert (base) elevation and their likely storage capacity. This led to a further detailed study by the same team (Ward et al. 2017b), where GIS mapping was used to interpret previous archaeological evidence with a sound engineering understanding of the principles of water distribution systems, identifying, for the first time, a technically feasible route for the Hadrianic Aqueduct and possible network connections linking major cisterns. Meanwhile, outside the city walls, Ruggeri et al. (2017) used GIS together with a digital elevation model and GPS records of field surveys of aqueduct remains to trace a detailed, contour-hugging route for the Valens Aqueduct, identifying its length and slope as well as its likely cross-section dimensions at various locations, based on a re-interpretation of previous field work.

\section{B-hydraulic structures}

Individual hydraulic structures such as the well-preserved castellum divisiorum at Nîmes have attracted attention for many years. Hauck and Novak (1988) presented a well-written paper containing a steady flow analysis of this structure, concluding that its design was a 
Table 2 Categories of subject matter

\begin{tabular}{ll}
\hline $\begin{array}{l}\text { Subject } \\
\text { category }\end{array}$ & Description \\
\hline A & $\begin{array}{l}\text { Hydraulic geometry-research concerned with a technical understanding of geometry relevant to } \\
\text { water flow, for example geographical information system (GIS) mapping studies of catchments }\end{array}$ \\
B & $\begin{array}{l}\text { Hydraulic structures-research trying to understand individual structures or classes of structure, } \\
\text { rather than systems of interconnected structures }\end{array}$ \\
C & $\begin{array}{l}\text { Flow in water systems-research trying to analyse the capacity of systems or the volume of water } \\
\text { actually flowing through them }\end{array}$
\end{tabular}

superb achievement to deal with the likely flows. Their technical appendix gives full details of the standard approaches used, incorporating Manning's equation, weir, orifice and gate discharge equations as well as a fuller application of Bernoulli's principle from which these are ultimately derived.

Meanwhile, Kessner et al. (1998) attempted to understand the complicated hydraulics of the magnificent third-century aqueduct and inverted siphon at Aspendos, Turkey. They presented archaeological details of the siphon structure, with dimensions, and carried out simple, Darcy-Weisbach steady pipe flow calculations to determine the hydraulic head (energy) loss in the structure. They then speculated that the positioning of the towers at bends in the aqueduct route might have been to resist the forces associated with the change in direction of the flow. Stone pipes with holes in the side, closed by a bung, were also noted and photographed.

Later, Ortloff et al. (2003) revisited Aspendos, with a much more involved analysis using CFD to model the structure, taking account of transient effects such as might have been encountered at the start-up of the siphon following construction or maintenance. The potential for pipe breakage due to pressure surge was considered, and it was claimed that the intermediate towers acted to damp transients, and thereby prevent their passage downstream. Considerable consideration was given to the possible meaning of statements in Vitruvius (see for example Rowland et al. 2007) and identified the controversial term colliquiaria cited in that work (Book 8, Chapter 6, Verse 6) with the holes in the pipes that Kessner et al. (1998) had photographed earlier. It is possible to interpret the claims of having resolved Vitruvius' meaning as somewhat ambitious, but the detailed engineering analysis of the Aspendos structure is not to be doubted.

Charles Ortloff's interest in CFD modelling of ancient structures continued with two quite similar studies of various aspects of the Nabataean remains at Petra (Ortloff 2005, 2014). He uses his detailed simulations to examine the design choices made, noting that, although not Roman per se, the Petra structures are contemporaneous with Roman systems and may have benefited from Roman expertise. Whilst outside the scope of this review, it is worth noting that Ortloff applied a CFD approach to many ancient structures in the nonRoman world, reported, together with versions of the ones reviewed here, in his book (Ortloff 2009). His study on the flow in the aqueducts at Ephesus is reviewed below.

A more simple study, concerned mainly with siphons generally, rather than any particular individual structure, is that of Smith (2007). This author conducted a significant technical discussion on stress in pipe materials and used a basic treatment of modern steady pipe flow theory based on the Darcy-Weisbach equation, noting that this was clearly not available in Roman times. He gave extensive coverage of ancient sources and archaeology, concerning among other things various methods of joining sections of lead pipes, further 
discussion on the holes found in stone pipes, and speculation on mechanical valves. Specifically, his discussion on the air holes at Aspendos suggests some analysis had been done, given flow velocities quoted and some discussion of the issue of transient forces due to water hammer; however, this analysis is not presented in the paper. However, Smith dismisses idea that holes were left open everywhere.

Steep dropshafts and related structures such as chutes and cascades, where the level of an aqueduct channel takes a step downward, are another type of structure, and one that has attracted particular interest from Hubert Chanson. His earlier studies (Chason 2000a, 2000b) present a good catalogue of relevant remains in the Western Empire and North Africa, and a report on laboratory experiments on a scale model of a dropshaft. This author's focus is on possible sub- to supercritical flow transitions relating to dropshafts, and he speculates on the use of stilling basins to address issues with this in some places. He comments that aeration of the water resulting from the eddying at these transitions might have been beneficial in closed conduits. In his first paper, Chanson (2000a) claims to have carried out a complete analysis, but there is not much detail given of how this was done. Technical material is presented on flows passing overshot and undershot gates in relation to depth, and there is a useful graph categorizing different structures by steepness. A well-argued case that design was standard across Empire is presented, but without a clear method or referencing to really support the claim. In a later paper, Chanson (2002) presents useful tabulated information on Roman dropshafts and details experimental and some analytical analysis showing good performance in low flows, risk of scour in intermediate flows where the nappe of the jet impacts on the channel roof at the outlet, and similar performance to modern structures in high flows.

Cistern arrangements were studied by Vannesse et al. (2014) in the context of Apamea in Syria. Three cisterns with inflow arrangements suggesting jets and outflows are reported, with steady-flow hand calculations carried out to examine the jet trajectories and the likely inflow and outflow rates; conceptual calculations for a terracotta-piped aqueduct are carried out, suggesting up to 20 similar arrangements of cistern could have been supplied from the source.

More recently, Ortloff (2018) considered the flow into and out of the castellum divisorium in Nîmes (France), noting the various arrangements of outlets from the castellum basin, and calculating the necessary aqueduct gradients to give critical flow. A CFD analysis was carried out to support the hand calculations. Continuing his theme of insight into Roman design methods, the author concludes that, in this case, the Roman engineers understood the impact of channel slope on the stability of flow in the castellum.

Finally, in studying the operation of Roman hydraulic structures, there are two studies looking not at water flow but at the flow of heat in baths. Basaran et al. (1998) made an early CFD study of Phaselis in Turkey, whilst more recently Oetelaar (2016) conducted a CFD analysis of heat flow in (the air of) a bath house, the stated aim of the study being to demonstrate how an engineering study with CFD can explain the environment in Roman bath houses in ways not possible from archaeology alone.

\section{C-flow in water systems}

The study of flow in aqueducts, including open channels and pipes, with a view to determining how much water flowed into Roman cities, is the area of our review that has attracted most engineering study thus far. At the more basic end of the analysis spectrum, Keenan-Jones' (2010) study of the Aqua Augusta around the Bay of Naples is 
essentially an archaeological survey of the aqueduct system and how it was used, with sources and destinations of water, but no hydraulic analysis; however, the author does make a few comments on likely flows based on contemporary spring discharge figures for the sources at the Acquaro Pelosi springs, establishing the precedents for considering the water available to flow into an aqueduct, rather than its capacity defined by its geometry, and for using modern spring flow data as a guide to past circumstances.

Hostetter et al. (2011) also did no specific hydraulic analysis, but they identified a promising line of inquiry by carrying out a detailed laboratory analysis of the deposition of travertine (also known as sinter, i.e. limestone being precipitated as a result of carbon gasification of calcium-rich spring water). Their study of the Baths of Caracalla in Rome led to conclusions about deposition rates and water sources, as well as dating and duration of flow beyond the last maintenance event during which travertine was removed.

The name of Trevor Hodge is well known to students of Roman water systems; in his earlier venture into the field, (Hodge 1984), he was concerned solely with the often controversial Roman unit of the quinaria, attempting to quantify this in modern terms. Hodge contended, with sound reasoning, that to Frontinus and other contemporary figures, the unit must have been related to the opening of a sluice gate, measuring the gap beneath it and the height of the water upstream of it, and relating these to the modern relationship $A C_{D} \sqrt{2 g h}, A$ being the area of the orifice, $C_{D}$ a coefficient, $h$ the height of the water, and $g$ the acceleration due to gravity $(9.81 \mathrm{~m} / \mathrm{s} / \mathrm{s})$. Later, Hodge turned his attention to the welldocumented castellum divisorium at Pompeii, with its unique and asymmetric arrangement of three channels (Hodge 1996). He performed simple mass balance calculations, enabling him to propose that the channels were equipped with sluice gates and used alternately, as the use of all of them at once would exceed the aqueduct supply. This is a theme that has been revisited more recently by Monteleone et al. (2021), discussed below. Hodge was convinced that the alternating use of the channels in the castellum was arrived at as a postconstruction adaptation by the users, as it is too complicated a design to have been thought up initially.

The quinaria also featured in Blackman's (1978) relatively early attempt to quantify the flow in the four great aqueducts of Rome, the Aqua Anio Vetus, the Aqua Marcia, the Aqua Claudia and the Aqua Anio Novus. He carried out steady open channel flow calculations using detailed channel geometry obtained from a wide variety of archaeological observations and some assumptions on channel slopes. He used friction equivalent to rough concrete and attempted to quantify the effect of flow rates quoted by Frontinus on the resulting depth and speed of flow along the length of the aqueducts, including sub/supercritical flow transitions. A constant flow rate value of Frontinus' quinaria of $0.48 \mathrm{~L} / \mathrm{s}$, based on work by Fenizio (1916), was assumed. The latter paper we have not reviewed, due to its age and it being written in Italian. Blackman's (1978) work is a very thorough paper and is an excellent start for any engineer wishing to work on the aqueducts of Rome.

Beaumont (2008) surveyed the possible water supplies for Housesteads Roman Fort on Hadrian's Wall, UK, which is situated in a high location and displays no obvious evidence of any aqueduct, although several small tanks are preserved in the fort. Noting the prevalence of rainfall in the area (to which the authors of this review can personally attest), Beaumont used modern rainfall statistics with assumed percentage runoff values for the roofs of the buildings to examine the possibility of supplying the fort garrison by rainwater harvesting. The analysis is a simple mass-balance, but leads to a plausible conclusion, albeit with some speculation on possible alternatives for which no physical evidence appears to exist. 
A relatively early presentation of steady open channel flow calculation applied to an aqueduct was presented by Lolos (1997), who studied the Hadrianic aqueduct of Corinth in Greece. Reflections on practicalities of construction such as service roads were presented, with considerable detail of hydraulic structures such as bridges and settling tanks. Steady open channel flow calculations lead this author to a flow estimate of $0.9 \mathrm{~m}^{3} / \mathrm{s}$, and consideration of the variation of water availability from the spring source over seasons was given, including flow measurements from the 1940s. Lolos also considered travertine deposits, noting that they were thin and unlikely to have affected flow all that much. A useful appendix on Roman aqueducts in Greece is also included. This is an excellent paper that pays sensible regard to engineering realities.

More recently, Ozis et al. (2014) reported a fairly simple analysis of four conveyance systems supplying Ephesus in Turkey, and encompassing baked clay pipes and masonry aqueducts. They assumed average slopes of sections and calculated pipe flows according to the Darcy-Weisbach approach with an assumed roughness height of $1 \mathrm{~mm}$ and open channel flows computed with Manning's equation with a roughness coefficient of 0.04, which is considerably higher than that used by other researchers on Roman aqueducts, corresponding in modern practice more to a meandering natural stream than to a plaster-lined channel. Ozis et al. understand the simplicity of their approach and recommend a more detailed analysis.

Still in the realm of hand-calculation, Vekemans et al. (2017) present an analysis of the unusual, wide, shallow open channel that runs north-south through the centre of Roman Perge in Turkey, using weir considerations to evaluate the flow emerging from the nymphaeum upstream and concluding that the stone blocks across the channel, placed every $7 \mathrm{~m}$ along its length, were not just decorative but necessary to raise the water level sufficiently to enter the east-west diversions that were part of the city's distribution system. This is an interesting if rather pedantically presented paper in terms of the hydraulics in it.

Finally, in terms of Manning's equation-type open channel flow calculations, an archaeological, topographical and hydraulic study of the Roman aqueduct of Kavala, Greece, is presented by Dermentzoglou et al. (2019). These authors used archaeological remains, together with a careful topographical survey, to interpret the entire route and slope of the $6500 \mathrm{~m}$ long aqueduct from the mountains to the city. They carried out hand calculations using a Manning's coefficient of 0.017 to estimate the maximum capacity of flow, and they conclude that the aqueduct would have given sufficient water for the estimated population during the Roman era. Earlier claims that the aqueduct fed an important cistern in the city are discounted due to the aqueduct entering the city at too low an elevation.

Turning to more difficult computations, the pipes of Ephesus were also the subject of further CFD analysis by Charles Ortloff and co-workers (Ortloff et al. 2001). They did computer simulations for long lengths of pipe, aiming to extract ideas about the design understanding of Roman water engineers. In an echo of Ortloff's earlier concern with the air holes in the pipes at Aspendos (see above), the conclusion drawn from his Ephesus study is that many design strategies such as restricting pipeline lengths were employed to avoid sub/supercritical flow transitions and reduce energy loss.

CFD was further used by Haut et al. (2007) for a study of a short length of aqueduct channel with two connected cisterns, in Apamea-the same system as that later studied by Vannesse et al. (2014) reviewed above. The authors derived energy loss coefficients by studying detailed flow patterns such as the formation of vortices. Estimates of flow were arrived at, showing the capacity of the aqueduct and observations were made about the effect of travertine deposits on wall friction and the possibility that the designers had allowed for increased depth because of this. The authors commented on the efficiency of 
many of the system components in terms of energy loss, the CFD analysis providing this insight.

Also involving computer modelling, this time using the industry-standard HEC-RAS river modelling software, Crapper, Ruggeri et al. (2016), working on the basis of the Ruggeri et al. (2017) GIS study previously reviewed, created a model of the Valens Aqueduct of Constantinople and estimated spring flow values for input, determining the aqueduct maximum carrying capacity and the location where this was first reached. Whilst this research demonstrated the usefulness of river modelling software to simulate open channel flow in Roman aqueducts, the input data was so simple that the conclusions could offer only limited insight. Recently, however, the work has been extended by Ruggeri (2018) and Crapper (2020) to include consideration of the water available in the catchment, the intake configuration and seasonal variations, resulting in estimates of the flow reaching the city of Constantinople on a month-by-month basis, and insight into questions that archaeology alone has not been able to answer regarding the configuration of the fourth- and fifth-century aqueduct channels close to the city.

On the issue of gaining insight into water distribution network configuration, the town of Pompeii has been the subject of much speculation, though apart from the work of Hodge (1996) already reviewed, none of this is quantitative. However, a very recent study by Monteleone et al. (2021) has addressed this, with careful hand calculations of the flow over the weir notches in Pompeii's many surviving lacus fountains, producing an estimate of the total flow required to supply this portion of the city's water use. The authors assert that this will provide a basis for better understanding the water distribution network, since the values of flow allow values of head loss to be calculated, defining the limits of which water towers could be connected to which fountains with far more certainty than the archaeology alone can do.

Poehler et al. (2018) and Motta et al. (2018) presented two conference papers examining not the water supply but the surface water drainage of Pompeii. Their study was the first attempt to quantify flows and evaluate the performance of an ancient city drainage network, and they employed the UK industry-standard urban drainage modelling application InfoWorks ${ }^{\mathrm{TM}}$ ICM, coupled with an ArcGIS topographic model and database. The water depths, flow velocities, and flow rates in Pompeii's streets during and after rainfall events were modelled, representing the streets with high kerbs as open channels with composite cross-section shapes, connecting at street intersections. Water was collected from city blocks that were treated as subcatchments. The model allowed understanding of the rationale behind water management mechanisms such as kerb stones and modified paving stones implemented by the Pompeians to stop, deviate, and drain away the street surface runoff and mitigate street flooding. The impact of house impluvia and cisterns on reducing street flooding through rainwater storage, especially in the drier summer months, was also quantified.

A completely different approach to trying to quantify flow in Roman aqueducts is that adopted by Keenan-Jones et al. (2015) and Motta et al. (2017), who have attempted to do so by analysing travertine deposits in the Aqua Anio Novus of Rome. The scientific study of travertine from the geological and dating perspective has been carried out previously, notably by Prof. Cees Passchier's group at Johannes Gutenberg Universität Mainz (see for example Sürmelihindi et al. 2013 and Surmelihindi et al. 2013). Keenan-Jones, Motta and their co-authors have extended this, however, to try and relate the layering of travertine deposition, the total build-up of travertine thickness, and the height and spatial distribution of deposits on the aqueduct floor and walls to the flow experienced over the years. The first paper (Keenan-Jones et al. 2015) used travertine to estimate the wetted perimeter of the 
Aqua Anio Novus for uniform flow calculations, coming up with a value of $1.4 \pm 0.4 \mathrm{~m}^{3} / \mathrm{s}$ as the latest flow rate (i.e. at the end of the aqueduct's operational life), which is a $25 \%$ reduction on the original capacity due to the build-up of travertine. Motta et al. (2017) further advanced this analysis with the aid of a GIS compilation of existing geometrical data from archaeology along the length of the aqueduct. They re-estimated at various locations the capacity loss due to travertine to be as much as $40 \%$ and carried out a HEC-RAS steady flow analysis looking at variation in velocity and depth along the aqueduct, attempting to correlate this to observations of travertine thickness. This sound engineering analysis highlights the promising nature of travertine analysis for recovering historic flow information, and has led to some interesting speculation on the possibility of using contemporary understanding of travertine deposition to explain possible design and operation responses to the problem by the ancient Romans.

Keilholz (2017) studied the Decapolis city of Gadara, Jordan, where a first-century BC Roman aqueduct was used until the eighth century. It had various branches distributing water to parts of the city, and there is evidence for sluice gate control structures. As well as presenting a detailed historical survey, the author applied the DHI commercial river modelling software MIKE 11 in a steady-state model and calibrated it against sinter marks to obtain likely flows in various parts of a 503 m-long section at the city end of the aqueduct. Sinter marks seem to have been interpreted at face value with no regard to maintenance, layering or seasonal variation. Earlier in the paper, the author discusses the flow from the springs in the pre-Roman era, using modern figures without very clear justification being presented. This is nevertheless a fascinating paper that again combines steady-state open channel flow modelling with sinter, further exploring the potential of this approach.

Finally, in the study of flow in conduits, Crapper and co-workers (article under review) have conducted an experimental investigation on two sections of Roman lead water pipe, part of a pipe recovered from a first century AD bath house at Corbridge in England near Hadrian's Wall. One section of pipe had a sleeved joint in its centre; the pipes were tested to determine the relationship between flow and head loss, allowing the wall roughness parameter that feeds into the Darcy-Weisbach equation to be quantified as $0.9 \mathrm{~mm}$ and, by comparison between the two sections of pipe, the local loss coefficient of the sleeved joint to be established as 1.159. It appears that this is the only experimental flow test ever carried out on genuine Roman conduits, other than one by Garbrecht (1982), reported by (Smith 2007), on some large earthenware pipes from the Madradag Aqueduct at Pergamon. In this latter case, however, no specific details of the investigation were included in Smith's work, and we have not been able to source a copy of the original 1982 paper, which is in German.

\section{Discussion}

The research reviewed here makes it apparent that a wide range of quantitative analysis methods are available for application to Roman water systems and their components. Many of these are relatively straightforward, certainly in terms of modern water engineering, and whilst a clear understanding of the principles being investigated is required, much of the software deployed by the authors of the more involved analyses is relatively user-friendly. Thus, members of the Archaeohydrology community, interested in pursuing hydraulic engineering analysis, should not be put off by any perceived difficulty. 
Of course, the study of a Roman water system requires a considerable degree of evidence for the layout and geometry of a system, and this evidence needs to be interpreted as a system configuration that existed during a specific period. This can be difficult to extract from an archaeological record of a system that evolved over time, which makes the contribution of archaeologists essential to the endeavour.

Nevertheless, the analysis of the water systems of modern cities has more in common with that of ancient ones than might first be thought. Modern urban water networks, at least in Europe, tend to have their origins in the nineteenth century; their construction records may always have been sketchy and successive reorganizations of the public authorities that care for them have often resulted in loss of records. Systems are added to and altered over the years, and on-site knowledge is in the heads of operatives who variously retire or are transferred. Therefore the modern hydraulic engineer, faced with the requirement to upgrade or retrofit an existing water system, is often faced with an archaeology-like task to determine its configuration, which is often supplemented by the interpretation of hand calculation or model results to gain insight on possible or impossible configurations of conduits under the ground or inaccessible. The first author of this review has specific experience of this when working on sewer networks (which, being driven by gravity, have a lot in common with Roman systems) in the UK cities of Lancaster, Sheffield and Glasgow.

The capacity of similar hydraulic analysis to shed insight on Roman water engineering design practice has been made clear, in particular by Ortloff's CFD work on Ephesus (Ortloff et al. 2001) and Petra (Ortloff 2014), by Haut et al. (2007) on Apamea and by Motta et al. (2017) on Rome's Aqua Anio Novus, and on specific issues of system configuration, as demonstrated by work on Constantinople (Crapper 2020) and Pompeii (Monteleone et al. 2021). These approaches are commended where there is sufficient physical evidence on which to base them.

The adoption of innovative methods such as the travertine analysis of Keenan-Jones et al. (2015) and Motta et al. (2017) to recover ancient flow information is also an encouraging sign, with potential for much wider influence than just on understanding the "hardware" of Roman water infrastructure; good information on flows and their variation over seasons, years, and longer timescales can potentially inform research on urbanization, societal changes, and potentially also climate change and the response of past civilizations thereto.

\section{Conclusion}

A review has been carried out of quantitative hydraulic engineering studies of Roman water systems, focusing on English language publications in the post-1970 period when engineering analysis attained a relatively modern form. The intention was to show how such analysis can contribute to understanding how ancient water systems actually worked - the amount of water that flowed, its variation over timescales, and the kinds of issues that its designers and operators might have faced, and in doing this, to further the new interdiscipline of Archaeohydrology.

The review has emphasized that many different forms of analysis have been employed in previous research, requiring different levels of engineering educational background to accomplish them. These range from steady flow calculations of a type regularly undertaken by undergraduate civil engineers to detailed Computational Fluid Dynamics and computer 
modelling of water networks that are generally undertaken by trained researchers or those with relevant specialist experience in industry.

Our review has highlighted that, even where data is quite limited, a considerable level of quantitative analysis is possible and can provide useful insights that archaeology alone cannot produce.

It is our hope that readers will be inspired by this study to work in a more interdisciplinary way, combining the excitement of archaeological discovery with the quantitative skills of hydraulic engineering to add yet further life to the story that the many remains of water systems in the region formerly occupied by the Roman Empire already relay to the succeeding generations of scholars who study them, and to the public who visit, ponder, and admire them.

We recommend that, in future, further reviews covering the engineering analysis of ancient water systems beyond the Roman Empire and published in languages other than English be completed, as they will surely add to the inspiration we hope we have provided.

Acknowledgements The authors gratefully acknowledge the contributions of Dr Francesca Ruggeri and Dr Kate Ward in suggesting some of the literature for possible review and inclusion.

Author contributions All authors contributed to the searching and reviewing of literature and the writing of the paper.

Funding This research was not supported by any funding.

Data availability This is a review of previously published work, all of which is available in the public domain in some form.

Code availability Not applicable.

\section{Declarations}

Conflict of interest The authors have no conflicts of interest to declare.

Open Access This article is licensed under a Creative Commons Attribution 4.0 International License, which permits use, sharing, adaptation, distribution and reproduction in any medium or format, as long as you give appropriate credit to the original author(s) and the source, provide a link to the Creative Commons licence, and indicate if changes were made. The images or other third party material in this article are included in the article's Creative Commons licence, unless indicated otherwise in a credit line to the material. If material is not included in the article's Creative Commons licence and your intended use is not permitted by statutory regulation or exceeds the permitted use, you will need to obtain permission directly from the copyright holder. To view a copy of this licence, visit http://creativecommons.org/licenses/by/4.0/.

\section{References}

Basaran T, Ilken Z (1998) Thermal analysis of the heating system of the Small Bath in ancient Phaselis. Energy Build 27(1):1-11. https://doi.org/10.1016/S0378-7788(97)00013-3

Beaumont P (2008) Water supply at Houseteads Roman Fort, Hadrian's Wall: the case for rainfall harvesting. Britannia 39:59-84. https://doi.org/10.3815/006811308785917114

Blackman DR (1978) The volume of water delivered by the four great aqueducts of Rome. Pap Br Sch Rome 46:52-72. https://doi.org/10.1017/S0068246200011417

Çeçen K (1996) The longest Roman water supply line. Türkiye Sınai Kalkınma Bankası, İstanbul

Chadwick A, Morfett J, Borthwick M (2013) Hydraulics in civil and environmental engineering. CRC Press, Boca Raton 
Chanson H (2000a) A hydraulic study of Roman aqueduct and water supply. Aust J Water Res 4(2):111-120 Chanson H (2000b) Hydraulics of Roman aqueducts: steep chutes, cascades, and dropshafts. Am J Archaeol 104(1):47-72. https://doi.org/10.2307/506792

Chanson H (2002) An experimental study of Roman dropshaft hydraulics. J Hydraul Res 40(1):3-12. https://doi.org/10.1080/00221680209499868

Crapper M (2020) The valens aqueduct of constantinople: hydrology and hydraulics. Water Hist 12:427448. https://doi.org/10.1007/s12685-020-00254-4

Crapper M, Ruggeri F, Ward K, Crow J (2016) A Steady Flow Hydraulic Model of the 4th and 5th Century Aqueducts Supplying Constantinople. 4th IWA International Symposium on Water and Wastewater Technologies in Ancient Civilizations. Coimbra, Portugal

Dermentzoglou D, Dadaki S, Avgoloupis I, Katsifarakis KL (2019) Technical study of the historical aqueduct of Kavala, Greece. Water Hist 11:233-252. https://doi.org/10.1007/s12685-019-00238-z

Fenizio D (1916) Sula portata degli antichi acquedotti romani e determinazione della quinaria. Giornale Del Genio Civile 14:227-331

Garbrecht G (1982) Die Wasserversorgung des antiken Pergamon. Mitteilungen der Technischen Universität Carolo-Wilhelmina zu Braunschweig, 18(11)

Hauck GF, Novak RA (1988) Water Flow in the Castellum at Nimes. Am J Archaeol 92:393-407. https:// doi.org/10.2307/505555

Haut B, Viviers D (2007) Analysis of the water supply system of the city of Apamea, using computational fluid dynamics. Hydraulic system in the north-eastern area of the city, in the Byzantine period. J Archaeol Sci 34(3):415-427. https://doi.org/10.1016/j.jas.2006.06.005

Hodge AT (1984) How did frontinus measure the quinaria? Am J Archaeol 88(2):205-216. https://doi. org/10.2307/504996

Hodge AT (1996) In Vitruvium Pompeianum: urban water distribution reappraised. Am J Archaeol 100(2):261-276. https://doi.org/10.2307/506904

Hostetter E, Fouke BW, Lundstrom CC (2011) The last flow of water to, and through, the Baths of Caracalla. J Anc Topogr/Riv di Topogr Antica 21:53-90

Keenan-Jones D, Motta D, Garcia MH, Fouke BW (2015) Travertine-based estimates of the amount of water supplied by ancient Rome's Anio Novus aqueduct. J Archaeol Sci Rep 3:1-10

Keenan-Jones D (2010) The Aqua Augusta and control of water resources in the Bay of Naples. 31st Conference of the Australasian Society for Classical Studies. Perth, Australia

Keilholz P (2017) Water supply and distribution in the ancient Decapolis city of Gadara. Water Hist 9:147-168

Kessner P, Piras S (1998) The pressure line of the aspendos aqueduct. Adalya II, Istanbul, pp 159-187

Lolos YA (1997) The hadrianic aqueduct of corinth (with an appendix on the Roman aqueducts in Greece). Hesperia 66(2):271-314

Maktav D, Crow J, Kolay C, Yegen B, Onoz B, Sunar F, Coskun G, Karadogan H, Cakan M, Akar I, Uysal C, Gucluer D, Geze B, Ince G (2009) Integration of remote sensing and GIS for archaeological investigations. Int J Remote Sens 30(7):1663-1673. https://doi.org/10.1080/014311609029090 26

Monteleone MC, Crapper M, Motta D (2021) The discharge of Pompeii public lacus fountains. Water Hist 13:189-216. https://doi.org/10.1007/s12685-021-00281-9

Motta D, Keenan-Jones D, Garcia MH, Fouke BW (2017) Hydraulic evaluation of the design and operation of ancient Rome's Anio Novus aqueduct. Archaeometry 59(6):1150-1174. https://doi.org/10. 1111/arcm.12303

Motta D, Poehler E, Keenan-Jones D (2018) A Quantitative Analysis of the Surface Drainage System at Pompeii. 5th International Landscape Archaeology Conference. Newcastle upon Tyne and Durham, United Kingdom

Oetelaar T (2016) CFD, thermal environments, and cultural heritage Two case studies of Roman baths. IEEE 16th International Conference on Environment and Electrical Engineering, Firenze, Italy

Orengo HA, Miro i Alaix C (2013) Reconsidering the water system of Roman Barcino (Barcelona) from supply to discharge. Water Hist 5:243-266. https://doi.org/10.1007/s12685-013-0090-2

Ortloff CR (2005) The water supply and distribution system of the Nabataean city of Petra (Jordan), 300 BC-AD 300. Camb Archaeol J 15(1):93-109. https://doi.org/10.1017/S0959774305000053

Ortloff CR (2009) Water engineering in the ancient world. Oxford University Press, Oxford

Ortloff CR (2014) Water engineering at Petra (Jordan): recreating the decision process underlying hydraulic engineering of the Wadi Mataha pipeline system. J Archaeol Sci 44:91-97. https://doi. org/10.1016/j.jas.2014.01.015

Ortloff CR (2018) The Pont du Garde aqueduct and castellum: insight into Roman hydraulic engineering practice. J Archaeol Sci Rep 20:808-817. https://doi.org/10.1016/j.jasrep.2018.05.021 
Ortloff CR, Crouch DP (2001) The urban water supply and distribution system of the Ionian city of Ephesos in the Roman imperial period. J Archaeol Sci 28(8):843-860. https://doi.org/10.1006/jasc.2000.0604

Ortloff CR, Kassinos A (2003) Computational fluid dynamics investigation of the hydraulic behaviour of the Roman inverted siphon system at Aspendos, turkey. J Archaeol Sci 30(4):417-428. https://doi. org/10.1006/jasc.2002.0851

Ozis U, Atalay A, Ozdemir Y (2014) Hydraulic capacity of ancient water conveyance systems to Ephesus. Water Supply 14(6):1010-1017. https://doi.org/10.2166/ws.2014.055

Poehler E, Motta D, Keenan-Jones D (2018) The Surface Drainage System at Pompeii. Roman Archaeology Conference (RAC) and Theoretical Roman Archaeology Conference (TRAC). Edinburgh, United Kingdom

Rowland ID, Howe TN, Dewar M (2007) Vitruvius pollio-ten books on architecture. Cambridge University Press, New York

Ruggeri F (2018) Engineering the Byzantine Water supply of Constantinople: mapping, hydrology and hydraulics of the long aqueducts outside the city. The University of Edinburgh, Edinburgh

Ruggeri F, Crapper M, Snyder JR, Crow J (2017) A GIS-based assessment of the Byzantine water supply system of Constantinople. Water Supply 17(6):1534-1543. https://doi.org/10.2166/ws.2017.062

Ruggeri F, Crapper M, Snyder JR and Crow J (2016) A GIS-based assessment of the Byzantine water supply system of Constantinople 4th IWA International Symposium on Water and Wastewater Technologies in Ancient Civilizations. Coimbra, Portugal

Smith NAF (2007) The hydraulics of ancient pipes and pipelines. Trans Newcom Soc 77(1):1-49. https:// doi.org/10.1179/175035207X163334

Surmelihindi G, Passchier CW, Spotl C, Kessener P, Bestmann M, Jacob DE, Baykan ON (2013) Laminated carbonate deposits in Roman aqueducts: origin, processes and implications. Sedimentology 60(4):961982. https://doi.org/10.1111/sed.12000

Sürmelihindi G, Passchier CW (2013) Sinter analysis. A tool for the study of ancient aqueducts. Historische Wasserleitungen gestern, heute, morgen: Internationales Symposium mit besonderer Berücksichtigung ihrer denkmalgerechten und betriebssicheren Erhaltung, Wien, 19.-23. Oktober 2011. G. Wiplinger. Leuven [u.a.], Peeters: 269-286

Vannesse M, Haut B, Debaste F, Viviers D (2014) Analysis of three private hydraulic systems operated in Apamea during the Byzantine period. J Archaeol Sci 46:245-254. https://doi.org/10.1016/j.jas.2014. 03.022

Vekemans O, Haut B (2017) Hydraulic analysis of the water supply system of the Roman city of Perge. J Archaeol Sci Rep 16:322-329. https://doi.org/10.1016/j.jasrep.2017.09.018

Ward KA, Crapper M, Altug K, Crow J (2017a) The Byzantine cisterns of Constantinople. Water Supply 17(6):1499-1506. https://doi.org/10.2166/ws.2017.053

Ward K, Crow J, Crapper M (2017b) Water supply infrastructure of Byzantine Constantinople. J Roman Archaeol 30:175-195. https://doi.org/10.1017/S1047759400074079

Publisher's Note Springer Nature remains neutral with regard to jurisdictional claims in published maps and institutional affiliations. 